\title{
Parental catastrophizing about their child's chronic pain: Are mothers and
}

fathers different?

Tanja Hechler $^{1 *}$, Tine Vervoort ${ }^{2}$, Maximiliane Hamann ${ }^{13}$, Anna-Lena Tietze ${ }^{1}$, Silja Vocks $^{3}$, Liesbet Goubert ${ }^{2}$, Christiane Hermann ${ }^{4}$, Julia Wager ${ }^{1}$, Markus Blankenburg ${ }^{1}$, Sandra Schroeder ${ }^{1}$, Boris Zernikow ${ }^{1}$

${ }^{1}$ Vodafone Foundation Institute and Chair for Children's Pain Therapy and Paediatric Palliative Care, Children's Hospital Datteln, Witten/Herdecke University, Germany

${ }^{2}$ Department of Experimental and Clinical Health Psychology, Ghent University, Ghent, Belgium

${ }^{3}$ Department of Clinical Psychology and Psychotherapy, Ruhr-University Bochum, Germany

${ }^{4}$ Department of Clinical Psychology, Justus-Liebig University, Gießen

\section{* Corresponding author:}

Tanja Hechler, PhD, Ms Psychol

Vodafone Foundation Institute and Chair of Children's Pain Therapy and Paediatric Palliative Care

Children's and Adolescents' Hospital Datteln/ Witten/Herdecke University

Dr.-Friedrich-Steiner-Str. 5

45711 Datteln, Germany

Phone: +49 (0) 2363-975-189

Fax: +49 (0) 2363-975-181

E-mail address: T.Hechler@kinderklinik-datteln.de 


\section{Abstract}

Preliminary evidence suggests that parental catastrophizing about their child's pain may be important in understanding both parental responses to their child's pain and the child's pain experience. However, little is known about potential differences between mothers and fathers. There were three aims of the present study addressing this lack of knowledge: i) to investigate the three-factor structure of the German version of the Parental Pain Catastrophizing Scale (PCS-P) (Goubert et al., 2006) in mothers and fathers of children with chronic pain, ii) to explore differences between mothers and fathers in parental catastrophizing, iii) to investigate the contribution of parental catastrophizing on the child's chronic pain problem and pain-related parent behavior.

In a sample of 128 mothers and fathers of paediatric chronic pain patients, the invariance of the PCS-P was evaluated. Results replicated the previously established three-factor structure (i.e. rumination, magnification and helplessness) in both groups. Mothers reported higher levels of catastrophizing as compared to fathers. Specifically, mothers and fathers differed on levels of rumination; the two groups did not differ in magnification and helplessness. Maternal but not paternal catastrophizing contributed significantly in explaining the child's pain intensity whereas neither mothers' nor fathers' catastrophizing were significantly related to the child's disability. Both maternal and paternal catastrophizing contributed significantly to heightened parental solicitous responses. Fathers' but not mothers' catastrophizing also contributed to heightened distracting responses. The present findings attest to the importance of maternal and paternal catastrophizing for the child's pain characteristics and pain-related parent behavior, which are both relevant for treatment conceptualization. 
Keywords: Parental catastrophizing, chronic pain, children and adolescents 


\section{Introduction}

Recent findings have indicated that pain catastrophizing in children with chronic pain, characterized by the child's tendency to highly focus and feel threatened by the pain, is of major importance in understanding deleterious pain outcomes (Crombez et al., 2003; Hermann et al., 2007; Vervoort et al., 2009). Catastrophizing has consistently been found to be positively related to heightened pain intensity and disability (Hermann et al., 2007; Vervoort et al., 2009).

However, not only the extent to which the child catastrophizes about the pain, but also the extent to which parents catastrophize about their child's pain may be relevant in understanding the child's pain experience. Like catastrophizing about one's own pain, parental catastrophizing may result in an increased focus upon the child's pain experience (Crombez et al., 2005). Preliminary evidence suggests that parental catastrophizing may not only increase emotional distress of parents (Goubert et al., 2006; Jordan et al., 2007), it may also lead to inappropriate parental responses (Lipani and Walker, 2006) which may, in turn, exacerbate the child's pain experience. Indeed, parental catastrophizing was associated with the child's pain characteristics in a group of children with musculoskeletal pain (Goubert et al., 2006).

Previous studies, however, are limited by its almost exclusive focus upon maternal catastrophizing (Goubert et al., 2006). Accordingly, there is little to no knowledge on the role of fathers' catastrophizing. In a sample of parents of schoolchildren who read short vignettes describing their child in pain, Goubert et al. (2008) found higher catastrophizing in mothers than fathers. Such a difference would be consistent with previous findings of sex differences in catastrophizing (Osman et al., 1997; Crombez et al., 2003). Females have been found to display higher scores in catastrophizing in healthy and clinical samples (Osman et al., 1997; Sullivan et al., 2000). Of interest, these sex differences mediate sex differences in clinical pain (Paller et al., 2009). 
Catastrophizing has been demonstrated to play a central role in explaining sex-based differences in clinical pain (Paller et al., 2009). Accordingly, mothers and fathers may not only differ in the extent to which they catastrophize about their child's pain, they may also differ in the extent to which catastrophizing accounts for the child's pain outcome.

The current study therefore aimed to investigate parental catastrophizing in a German sample of mothers and fathers of pediatric chronic pain patients. There were three objectives of the study: First, we aimed to investigate the invariance of the three-factor structure of the Parental Pain Catastrophizing Scale (PCS-P) in both parents. We assumed to find a similar factor structure in both samples indicative of the PCS-P measuring the same processes in both parents. Second, differences in maternal and paternal catastrophizing were investigated. We expect mothers' level of catastrophizing to be higher as compared to fathers' catastrophizing. Third, we investigated the contribution of parental catastrophizing on the child's chronic pain problem and pain-related parent behavior and explored differences between mothers and fathers. We expect significant contribution of both maternal and paternal catastrophizing on child's pain characteristics and on pain-related parent behavior. 


\section{Method}

\subsection{Participants}

Children with chronic pain warranting clinical intervention, and their parents were consecutively recruited from a tertiary pediatric pain clinic (Vodafone Foundation Institute and Chair for Children's Pain Therapy and Paediatric Palliative Care, VIKP) between September 2008 and February 2009. Inclusion criteria entailed (1) the presentation to our tertiary institute due to unsuccessful treatment in primary care, (2) age between 8 and 17 years, (3) an appropriate comprehension of German, (4) no underlying malignant disease and (5) availability of both mothers' and fathers' reports on the same child. All children and adolescents were accompanied by an adult who was identified as primary caregiver. A total of 230 children and their primary caregiver presented to the institute for treatment. Six children and their parents (3\%) denied participation in the present study. Fifty-three children (23\%) did not fulfill inclusion criteria of the study. Specifically, 26 children (11\%) suffered from a lifelimiting disease, 15 children were too young (7\%), 3 children (1\%) did not have an appropriate comprehension of German, and 9 children (4\%) cancelled the scheduled appointment. Two children and their parents delivered incomplete questionnaires (more than $50 \%$ of the items missing) (0.9\%). This resulted in a sample of 169 children and adolescents. Thirty-four mothers and seven fathers were single parents and were excluded since data of only one parent were available. This resulted in a final sample size of 128 children ( 80 girls and 48 boys; mean age=11.9 years, $\mathrm{SD}=2.5$; range $=8-17$ ), 128 mothers (mean age $=42.1$ years, $\mathrm{SD}=4.4$; range: $29-52$ ) and 128 fathers (mean age $=44.3$ years, $S D=5.5$; range: $24-59$ ). Statistical analyses revealed that study participants and participants excluded due to available data of only one parent did not differ in child's sociodemographic data and child's pain 
characteristics (i.e., mean pain intensity, pain-related disability and school absence) (p's >.05).

The majority of the children suffered from headache $(\mathrm{N}=97,76 \%)$ followed by abdominal pain ( $\mathrm{N}=15,12 \%$ ) (Table $\mathrm{S} 1)$. Mean pain duration of the child was 32 months $(S D=32.4)$. In 10 adolescents the pain duration was less than 3 months (range: 1-2 months). However, we included them into the present study for two reasons: they reported severe interferences in their daily life (such as school absence, social withdrawal). In addition, defining pediatric chronic pain simply by temporal criteria has been criticized recently (Huguet and Miro, 2008).

The majority of the parents were living together (90\%). Fathers worked mainly fulltime $(93 \%)$ whereas most of the mothers worked either part-time (52\%) or were unemployed at present (35\%).

Due to a small amount of missing data, there were minor variations in sample size across analyses (i.e., $N=126$ to $N=128$ ). Single missing values in the questionnaires were assigned using two-way procedure according to Sijtsma and van der Ark (, 2003) with missing values of a respondent $i$ on item $j$ are substituted with the person's mean score + overall item mean - overall mean. One to four items were imputed dependent on the questionnaire. On average, there were less than 10 imputations across all measures.

Please insert Table S1 here.

\subsection{Procedure}

Parents' and children completing the questionnaires was part of their clinic visit. Specifically, children and parents who qualified for participation in the study were sent a battery of questionnaires by mail prior to their first appointment at the VIKP. They were asked to send back the questionnaires within the following two weeks. On 
retrieval of the questionnaires, an appointment was scheduled with the families. The battery entailed the standard diagnostic measures of the VIKP, i.e., the assessment of the child's pain characteristics and pain-related disability by use of the German Pain Questionnaire for Children and Adolescents (DSF-KJ (Schroeder et al., 2009)). In addition to the standard battery, families were sent two copies (one for the mother and a second for the father) of the German version of the Parental Pain Catastrophizing Scale (PCS-P) and the Pain-Related Parent Behavior Inventory (PPBI) (Hermann et al., 2008) at the same time of the battery. A brief letter explained the purpose of the present study to the families and parents were instructed to complete the questionnaires independently. All families provided informed consent according to ethical guidelines of the Ethics Committee of the Witten/Herdecke University. Participants were not compensated for participation.

\subsection{Measures}

\subsubsection{Child and adolescent measures}

\subsubsection{Pain intensity}

Adolescents (aged 11-18 years) reported their pain intensity retrospectively during the preceding four weeks on a numeric rating scale (NRS; with $0=$ no pain to $10=$ maximal pain). Children (aged 8-10 years) reported their pain intensity retrospectively using the Faces Pain Scale - Revised (FPS-R) (Hicks et al., 2001) which was transformed into the following numeric rating scale -scores 0-2-4-6-8-10 for comparison with adolescents' ratings. Von Baeyer et al. (2009) recently provided support for the concordance of the NRS with other well-validated scales such as the FPS-R and the Visual Analogue Scales.

\subsubsection{Pain-related disability}

Adolescents reported pain-related disability using the Paediatric Pain Disability Index (P-PDI) (Hübner et al., 2009). Where child reports were not available we used 
parental reports $(n=41$ children aged 9 years on average $(S D=0.8))$. The P-PDI assesses disability in daily activities due to pain on 12 items rated on a 5-point scale ( $1=$ never to $5=$ =always). To obtain the total score all items are summed. Daily activities comprise activities such as going to school, doing homework, engaging in physical activity, and sleeping. In a sample of pediatric chronic pain patients suffering from chronic pain, reliability of the P-PDI (Cronbach's $\alpha=0.87$ ), factorial validity and construct validity were demonstrated (Hübner et al., 2009). Reliability was high in the present sample with Cronbach's ó $=0.90$.

\subsubsection{Parental measures}

\subsubsection{Parental catastrophizing about their child's chronic pain}

Parental catastrophizing was assessed with the German version of the Parental Pain Catastrophizing Scale (PCS-P) (Goubert et al., 2006). This scale was translated into German following the guidelines of cross-cultural validation of self-report measures including translation and back-translation of the questionnaire (Beaton et al., 2000). The PCS-P consists of 13 items describing different thoughts and feelings that parents may have when their child is in pain. Parents rate the extent to which they experience each of the thoughts and feelings using a 5-point scale $(0=$ not at all, 4=extremely). The PCS-P yields a total score that can range from 0 to 52 , and three subscale scores for rumination ("When my child is in pain, I can't keep it out of my mind"), magnification ("When my child is in pain, I wonder whether something serious may happen") and helplessness ("When my child is in pain, there is nothing I can do to stop the pain"). In a sample of Dutch parents of schoolchildren $(N=205)$ and English parents of children with chronic pain $(N=107)$ an oblique factor-structure emerged to best fit the data in both parent samples (Goubert et al., 2006). The total PCS-P score and the three subscales were all internally consistent with Cronbach's $\alpha$ coefficients ranging from $\alpha=.81$ to $\alpha=.93$. In addition, criterion validity was 
demonstrated through significant relationship with child's pain characteristics, parenting stress and parental emotional distress (Goubert et al., 2006).

\subsubsection{School absence}

School absence due to pain condition was assessed via parental report as the number of days missed at school within the preceding three months (Schroeder et al., 2009).

\subsubsection{Pain-related parent behavior}

Pain-related parent behavior was assessed with the Pain-Related Parent Behavior Inventory (PPBI) (Hermann et al., 2008). The PPBI assesses three dimensions of pain-related parent behavior: solicitous responses (6 items), discouraging responses (7 items) and distracting responses (4 items). For all items, respondents are asked to indicate how often the described parent behavior occurs when the child is in pain on a 5-point Likert scale (ranging from $1=$ never to $5=$ very often). Reliability and validity of the PPBI have been demonstrated (Hermann et al., 2008). The three subscales of the PPBI were all internally consistent in the present sample with Cronbach's $\alpha$ coefficients ranging from $\alpha=.72$ to $\alpha=.79$.

\section{Statistical analyses}

First, the three-factor structure of the PCS-P was tested within the sample of mothers and cross-validated within the sample of fathers. The goodness-of-fit of the three-factor structure demonstrated by Goubert et al. (Goubert et al., 2006) was evaluated by means of the maximum likelihood algorithm. Model fit of the three-factor structure across mothers and fathers was estimated by use of a) the Chi ${ }^{2}$ divided by the degrees of freedom (CMIN/DF), b) the comparative fit index (CFI), c) root mean squared error of approximation (RMSEA), and d) the goodness of fit index (GFI). CMIN/DF ratios between 2 and 5 indicate a reasonable fit (Marsh and Hocevar, 1985). A RMSEA value of 0.05 indicates a close fit and values up to 0.08 represent a 
reasonable error of approximation in the population (Browne and Cudeck, 1993). GFI values greater than 0.90 indicate an adequate fit (Tanaka and Huba, 1985).

Second, to examine whether the three-factor structure of the PCS-P was invariant across mothers and fathers, a multi-sample analysis was conducted (Byrne, 2004). This analysis provides evidence whether or not the PCS-P is equivalent for mothers and fathers. A restrictive model was tested by equating the number of factors, the factor loadings, the factor variances, the factor covariances, and the three error covariances (Byrne, 2004). Descriptive statistics and intercorrelations of the subscales were computed separately for mothers and fathers using SPSS Version 17.0. Internal consistency of the total scale and the resulted subscales were determined by computing Cronbach's $\alpha$.

We computed a paired samples T-test to compare maternal and paternal catastrophizing (total score), and a repeated measures MANOVA to compare the three subscales between parents. Analyses for paired samples were used since two measures (mothers' and fathers' rating) from one person (catastrophizing about their child's pain) were compared (Howell, 2010). A repeated measures MANOVA is an extension of a paired samples T-test and allows controlling for an inflated Type I error. It is especially powerful if the dependent variables (here the PCS subscales) are correlated (see Table 2).

Finally, a series of hierarchical regressions were computed for mothers and fathers separately to determine the unique contribution of parental catastrophizing a) to the child's pain intensity, disability, and school absence, and b) to pain-related parent behavior. In a first step, age and gender ( 0 =boys, $1=$ girls) (step 1) were entered to control for demographic variables. In a subsequent step, pain duration and pain intensity (step 2) - the latter for the analysis for parent pain-related behavior only - were entered to control for pain severity. Finally, the total PCS-P score (step 
3) was entered to investigate the contribution of parental catastrophizing. All continuous predictor variables were centered (Holmbeck, 2002). Prior to the regressional analyses we computed bivariate correlations between parental catatsrophizing, child's pain characteristics and pain-related parent behavior for mothers and fathers, separately. Those variables displaying significant relationships were then included in the regressional analyses.

\section{Results}

\subsection{Child's characteristics}

The majority of the children and adolescents suffered from headache (76\%). Children and adolescents reported severe pain intensity and demonstrated interferences in their daily lives as reflected by the amount of children displaying school absence (71\%) and the P-PDI mean scores (Table S1).

\subsection{Factor structure of the German version of the PCS-P}

Table 1 presents the goodness-of-fit indices for the three-factor structure of the PCS-P for mothers and fathers, separately. Initially, the three-factor structure in the mothers' sample did not provide a good model fit (Table 1, Model 1). Modification indices provided by the AMOS output suggested that the model could be substantially improved by allowing residual correlation between item 1 ("When my child is in pain, I worry all the time about whether the pain will end.") and 5 ("When my child is in pain, I can't stand it anymore.") (Table 1; Model 1 a modified). These residual correlation means that the correlation between the two items is stronger than the correlations between the remaining items of the scale. Allowing this pair of correlation may be justified as these two items belong to the same subscale (helplessness) and share some redundancy in content. When the model was modified, model-fit increased substantially but still provided not a good fit (Table 1; Model 1 a modified). Allowing two additional modification indices - all correlations on 
the same subscale (helplessness) - between item 2 ("When my child is in pain, I feel I can't go on like this much longer") and item 3 ("When my child is in pain, it's terrible and I think it's never going to get better ") and item 2 and 5 resulted in a good model fit (Table 1; Model $1 \mathrm{c}$ modified).

For fathers, the modified three-factor model (Model $1 \mathrm{c}$ modified, Table 1) resulted in a good model fit. The standardized factor loadings of the modified three-factor model for mothers and fathers are shown in Figure 1.

Please insert Table 1 and Figure 1 here.

\subsection{Invariance of the factor-structure of PCS-P for mothers and fathers}

To examine whether the modified three-factor model (model $1 \mathrm{c}$; Table 1) was invariant across mothers and fathers, a multi-sample analysis was conducted. The model was fit separately for mothers and fathers. A restrictive model was tested by equating the number of factors, the factor loadings, the factor variances, the factor covariances, and the three error covariances. Three goodness-of-fit indices indicated an adequate fit $(\mathrm{CMIN} / \mathrm{DF}=1.381 ; \mathrm{RMSEA}=0.039 ; \mathrm{CFI}=0.969)$, and one goodness-offit index an almost adequate fit $(\mathrm{GFI}=0.898)$. These findings suggest that the model is stable in both samples for the number of factors (invariant factor number), the contribution for the 13 PCS-P items to their respective factors (invariant factor loadings), the factor variance (invariant for factor variances), the intercorrelations between the factors (invariant for factor covariances) and the three error covariances (invariant error covariances).

\subsection{Descriptives and intercorrelations of the PCS-P subscales}

Means, standard deviations, intercorrelations, quartiles and internal consistencies of the three subscales for mothers and fathers are presented in Table 2. The PCS-P subscales were internally consistent and highly correlated in both samples. 
4.5 Differences in parental catastrophizing between mothers and fathers

Mothers displayed higher parental catastrophizing (Total score, $T(\mathrm{df}=127)=1.99$, $p=.049$ ). Based on the results of the MANOVA, this was due to more rumination thoughts in mothers than in fathers $(F(1,127)=11.83, p=.001)$. Mothers and fathers did not differ in magnification and helplessness thoughts (Table 2).

4.6 Maternal and paternal catastrophizing and their contribution to the child's pain characteristics

Table 3 depicts the bivariate relationships between maternal and paternal catastrophizing and the child's pain characteristics.

Please insert Table 3 here.

Mothers. Catastrophizing was positively related to the child's pain intensity. Specifically, there was a significant positive relationship between the total score (PCS-P total score) and rumination thoughts and the child's pain intensity.

Catastrophizing was unrelated to the child's pain-related disability (PPDI) and school absence.

Fathers. Catastrophizing (total score and subscales) was unrelated to the child's pain characteristics.

Within the subsequent regression analysis, mother's catastrophizing accounted for a significant amount of variance of the child's pain intensity beyond the contribution of the child's age, sex and pain duration $(\beta=0.19, t=2.00, p=.048)$ (Table 4).

Please insert Table 4 here.

4.6 Relationship between pain-related parent behavior and parental catastrophizing

Table 5 depicts the interrelationships between parental pain-related behavior and parental catastrophizing. 
Mothers. Solicitous responses were significantly related to catastrophizing thoughts (total score and three subscales). Discouraging responses were positively related to helplessness thoughts.

Fathers. Solicitous and distracting responses were both positively related to catastrophizing (total score and three subscales).

Please insert Table 5 here.

4.6 Maternal and paternal catastrophizing and their contribution to pain-related parent behavior

Mothers. Within regressional analyses, the child's age contributed significantly to maternal solicitous responses suggesting that mothers displayed more solicitous responses the younger the child $(\beta=-0.21, t=-2.23, p=.028)$ (Table 6). Maternal catastrophizing accounted significantly for solicitous responses beyond the effect of the child's age $(\beta=0.27, t=2.95, p=.004)$ indicating that higher catastrophizing was related to more solicitous behavior. Mothers' catastrophizing did not significantly predict distracting and discouraging responses. The child's sex contributed significantly to maternal discouraging responses suggesting that mothers reported more discouraging responses towards boys than towards girls $(\beta=-0.21, t=-2.16$, $p=.033)$.

Fathers. Similar to mothers, fathers displayed more solicitous responses the younger the child $(\beta=-0.20, t=-2.39, p=.019)$. Also, sex had a significant contribution indicating that fathers reported higher levels of solicitousness to boys $(\beta=-0.20, t=-$ 2.46, $p=.016$ ) than to girls. Paternal catastrophizing accounted significantly for solicitous responses $(\beta=0.45, t=5.57, p<.001)$ and distracting responses $(\beta=0.21$, $t=2.26, p=.026$ ) beyond the effect of the child's age and gender, indicating that higher levels of paternal catastrophizing contribute to higher levels of solicitous and 
distracting responses. Fathers' catastrophizing was not significantly related to discouraging responses.

Please insert Table 6 here. 


\section{Discussion}

This study furthers our understanding on the impact of maternal and paternal catastrophizing upon pain characteristics for children and adolescents suffering chronic pain and upon pain-related parent-behavior. The findings of the present study can be readily summarized: First, although mothers and fathers show differences in parental catastrophizing, the nature of the PCS-P is similar for mothers and fathers. Second, differences in maternal and paternal catastrophizing appeared to be quantitative with no differences in the factor structure of the PCS-P; mothers' level of catastrophizing was significantly higher than fathers'. Subscale-analyses indicated this difference was due to higher levels of rumination. Third, only maternal catastrophizing contributed to a small degree to the child's pain intensity while other pain characteristics were unrelated to mothers and fathers level of catastrophizing. Fourth, catastrophizing of both mothers and fathers contributed strongly to parental solicitous behavior towards the child beyond other variables. Fifth, fathers', but not mothers' catastrophizing was related to distracting behavior.

Of interest, mothers and fathers share similarities in catastrophizing, but also manifest some differences. When directly compared, the three-factor structure of the PCS-P was shown to be invariant in mothers and fathers providing evidence that the PCS-P measures the same processes in both parents. Consistent with this, intercorrelations and internal consistencies of the subscales were similar in mothers and fathers. Mothers were catastrophizing to a greater degree than fathers. This was due to more ruminating thoughts in mothers (i.e. persistent thoughts about the child's pain). This finding is in accordance with sex differences in ruminating thoughts in adult (Sullivan et al., 1995; Osman et al., 1997; Sullivan et al., 2000; Osman et al., 2000) and paediatric samples (Crombez et al., 2003). Possibly, mothers display greater anxiety about their child in pain which may account for greater rumination. In 
line with this, rumination has been shown to be positively associated with anxiety in clinical samples (Watkins, 2009), and anxious mothers have been found to catastrophize to a greater degree than non-anxious mothers (Whaley et al., 1999).

These differences in maternal and paternal catastrophizing are important in understanding the child's pain characteristics. Within the present sample, we found that mothers' but not fathers' catastrophizing positively contributed to the child's pain intensity. The fact that mothers tend to ruminate more is in line with this finding. Sullivan et al. (2001) have argued that it is particularly rumination thoughts that may increase the attentional bias towards the pain experience. Thus, ruminating thoughts in mothers may result in sustained attention on the child's pain. Given that the child's pain may thus be the focus of the mother's perception, the child's pain intensity may be reinforced through mother's attention as suggested in the operant model of chronic pain (Fordyce, 1976).

Our results differ from a previous study into parental catastrophizing (Goubert et al., 2006). Compared to Goubert's sample of 107 parents of children with chronic musculoskeletal pain (Goubert et al., 2006), parents in the present study were catastrophizing to a lesser degree as demonstrated by lower quartiles (e.g., quartile 50 for the total PCS-P in Goubert's sample was $M=29.0$ compared to $M=23.0$ for mothers and $M=22.0$ for fathers in the present study (Table 2)). Also, in contrast to results from Goubert et al., neither mothers' nor fathers' catastrophizing did significantly contribute to the child's disability. These differences might be due to discrepancies in the sample composition. Goubert's sample consisted mainly of mothers (95\%) and children were mostly suffering from musculoskeletal pain (Goubert et al., 2006). Here, a large sample of mothers and fathers was investigated separately and approximately $80 \%$ of the children in the present study were suffering from chronic headache. In children with musculoskeletal pain, pain interferes with 
daily physical activity thus making the chronic pain experience more observable than in children with chronic headache. This observable pain behavior may trigger higher catastrophizing thoughts in parents as suggested in the empathy model by Goubert et al. (2005). The differences in sample composition may also explain the lack of relationship between parental catastrophizing and disability in the present study. Possibly, parents of children with musculoskeletal pain may be more inclined to restrict the child's activities because they fear further injury more than parents with children suffering from headache (Palermo and Chambers, 2005).

This relates to the question if catastrophizing mothers behave differently towards their child than catastrophizing fathers. The present findings suggest that both mothers and fathers who scored high on catastrophizing reported greater solicitous responses towards their child. Both maternal and paternal catastrophizing significantly accounted for solicitous responses towards the child (15\% and 30\% explained variance, respectively). Solicitous responses entailed taking special care of the child, taking over his/her chores or duties and treating the child especially nice (Hermann et al., 2008). The present data only allow for preliminary explanations as to the parental response pattern. Parental catastrophizing may lead to parental distress due to the high threat value of the child's pain (Goubert et al., 2008). Catastrophizing parents faced with their inability to relieve the child's pain (Goubert et al., 2006; Jordan et al., 2007) may chose solicitous responses as an attempt to solve the child's pain problem. Future research is warranted into the consequences of these behavioral patterns. Possibly, solicitous responses may results in a lack of individuation and a way to delay encroaching adulthood resulting in an aggravation of the child's pain problem (Logan et al., 2006).

Of interest, catastrophizing fathers displayed more distracting responses such as suggesting playing with the child. This difference between mothers and fathers may 
be viewed in light of sex differences in pain-related coping (for a review see (Fillingim et al., 2009). It is now well established that there are significant differences in the way men and women cope with pain with males using more behavioral distraction compared to females. Possibly, these sex differences in coping with own pain experiences may also be reflected in different parental behavioral responses towards one's child with chronic pain.

Interestingly, the child's sex contributed to maternal and paternal pain-related behavior. Specifically, mothers reported more discouraging responses towards boys than towards girls. Fathers reported higher levels of solicitousness towards boys compared to girls. Discouraging responses entail responses such as not taking pain seriously or being hesitant about believing the child (Hermann et al., 2008). This finding may reflect gender role expectations. Robinson et al. (2003) found that women are perceived to have more pain than men. Gender stereotypic expectations of pain tolerance (such as the typical man compared to the typical woman) accounted for these sex differences suggesting that men are expected to have higher pain endurance than women. Possibly, mothers may show reluctance to take their sons' pain seriously because they expect their sons to endure pain and shape their pain behavior accordingly.

Fathers report higher levels of solicitous responses towards boys than towards girls. This contrasts with findings from Goubert et al.(2008). In their study in parents of schoolchildren, they found lower sympathy and concern in fathers than in mothers when reading short vignettes describing their child in pain. The short vignettes did not vary the child's gender. Possibly, fathers react solicitously when faced with their sons in pain. It is a matter of future research to determine the factors that modulate paternal responses towards their sons' and daughters' pain. Candidate related 
factors are increased empathy for pain towards their sons and getting used to girls' more frequent pain complaints(Sasmaz et al., 2004; Kröner-Herwig et al., 2007).

There are some issues to consider in evaluating this research. First, the study was cross-sectional, and correlations should not be confused with causal effects. This relates to the relationship between mothers' catastrophizing and the child's pain as well as to parents' catastrophizing and pain-related parent responses. Second, the additional value of mothers' catastrophizing in explaining the child's pain intensity beyond gender, age and pain duration was low, and requires replication. Third, to disentangle the relationship between maternal and paternal catastrophizing, child's pain characteristics and pain-related parent behavior several factors warrant further investigating which were not assessed in the present study such as parental emotional distress (Goubert et al., 2008), the sense of knowing of the child's pain (Goubert et al., 2005; Vervoort et al., 2008a) and the pain expression of the child when mother or father are present (Vervoort et al., 2008b). Fourth, given that $76 \%$ of the children suffered from headache the present data are primarily representative of a headache population. Future studies comparing parents' of children suffering various pain diagnoses are needed to generalize the present findings.

In conclusion, mothers and fathers show quantitative differences in parental catastrophizing. Mothers catastrophize to a higher degree than fathers due to greater ruminating thoughts about their child's chronic pain. Maternal catastrophizing was related to higher pain intensity, while other pain outcomes were unaffected by parental catastrophizing. Both maternal and paternal catastrophizing were related to parental solicitous responses towards the child. The causal quality of these relationships and of the differences between mothers and fathers remain to be determined in future studies. Answers to these questions may help to develop interventions targeting maternal and paternal catastrophizing and then to evaluate 
the extent to which such interventions actually impact on pain outcome in children.

As a result, specifically tailored interventions for mothers and fathers could be developed. 


\section{Acknowledgements}

The authors like to thank Stephanie Herr for her statistical advice. 


\section{References}

Beaton, DE, Bombardier, C, Guillemin, F \& Ferraz, MB. Guidelines for the process of cross-cultural adaptation of self-report measures. Spine 2000;24:3186-3191.

Browne, MW \& Cudeck, R. Alternative ways of assessing model fit. In Bollen, KA \& Long, JS, editors. Testing structural equation models. Newbury Park: Sage; 1993. p. $136-159$.

Byrne, BM. Testing for multigroup invariance using AMOS graphics: A road less traveled. Structural Equation Modeling: A Multidisciplinary Journal 2004;11:272300.

Crombez, G, Bijttebier, P, Eccleston, C, Mascagni, T, Mertens, G, Goubert, L \& Verstraeten, K. The child version of the pain catastrophizing scale (PCS-C): A preliminary validation. Pain 2003;104:639-646.

Crombez, G, van Damme, S \& Eccleston, C. Hypervigilance to pain: An experimental and clinical analysis. Pain 2005;116:4-7.

Fillingim, RB, King, CD, Ribeiro-Dasilva, MC, Rahim-Williams, B \& Riley, JL3. Sex, gender, and pain: a review of recent clinical and experimental findings. J Pain 2009;10:447-485.

Fordyce, WE. Behavioral methods for chronic pain and illness. St. Louis: Mosby; 1976.

Goubert, L, Craig, KD, Vervoort, T, Morley, S, Sullivan, MJL, Williams, AC, Cano, A \& Crombez, G. Facing others in pain: The effects of empathy. Pain 2005;118:285288.

Goubert, L, Eccleston, C, Vervoort, T, Jordan, A \& Crombez, G. Parental catastrophizing about their child's pain. The parent version of the Pain Catastrophizing Scale (PCS-C): A preliminary validation. Pain 2006;123:254-263. 
Goubert, L, Vervoort, T, Sullivan, MJL, Verhoeven, K \& Crombez, G. Parental emotional responses to their children's pain: the role of dispositional empathy and parental catastrophizing about their child's pain. J Pain 2008;9:272-279.

Hermann, C, Hohmeister, J, Hohmeister, J \& Flor, H. Dimensions of pain-related parent behavior: Development and psychometric evaluation of a new measure for children and their parents. Pain 2008;137:689-699.

Hermann, C, Hohmeister, J, Zohsel, K, Ebinger, F \& Flor, H. The assessment of pain coping and pain-related cognitions in children and adolescents: Current methods and further development. J Pain 2007;8:802-813.

Hicks, CL, von Baeyer, CL, Spafford, PA, van Korlaar, I \& Goodenough, B. The Faces Pain Scale - Revised: Toward a common metric in pediatric pain measurement. Pain 2001;93:173-183.

Holmbeck, GN. Post-hoc probing of significant moderational and mediational effects in studies of pediatric populations. J.Pediatr.Psychol. 2002;27:87-96.

Howell, DC. Statistical methods for psychology, 7th edition. Belmont, CA: Wadsworth Pub Co; 2010.

Hübner, B, Hechler, T, Dobe, M, Damschen, U, Kosfelder, J, Denecke, H, Schroeder, S \& Zernikow, B. Pain-related disability in adolescents suffering from chronic pain: Preliminary examination of the Pediatric Pain Disability Index (P-PDI) [Schmerzbezogene Beeinträchtigung bei Jugendlichen mit chronischen Schmerzen: Erste Überprüfung des Pediatric Pain Disability Index (P-PDI)]. Der Schmerz 2009;23:20-32.

Huguet, A \& Miro, J. The severity of chronic paediatric pain: An epidemiological study. J Pain 2008;9:226-236. 
Jordan, AL, Eccleston, C \& Osborn, M. Being a parent of the adolescent with complex chronic pain: An interpretative phenomenological analysis. Eur J Pain 2007;11:49-56.

Kröner-Herwig, B, Heinrich, M \& Morris, L. Headache in German children and adolescents: a population-based epidemiological study. Cephalalgia 2007;27:519527.

Lipani, TA \& Walker, LS. Children's appraisal and coping with pain: Relation to maternal ratings of worry and restriction in family activities. J Pediatr Psychol 2006;31:667-673.

Logan, D, Guite, JW, Sherry, DD \& Rose, JB. Adolescent-parent relationship in the context of adolescent chronic pain conditions. Clin J Pain 2006;22:576-583.

Marsh, HW \& Hocevar, D. Application of confirmatory factor analysis to the study of self-concept: First- and higher-order factor models and their invariance across groups. Psychol Bull 1985;97:562-582.

Olson, CL. Comparative robustness of six tests in multivariate analysis of variance. J Am Stat Assoc 1974;69:894-908.

Osman, A, Barrios, FX, Gutierrez, PM, Kopper, BA, Merrifield, T \& Grittmann, L. The Pain Catastrophizing Scale: further psychometric evaluation with adult samples. J Behav Med 2000;23:351-365.

Osman, A, Barrios, FX, Kopper, BA, Hauptmann, W, Jones, J \& O'Neill, E. Factor structure, reliability, and validity of the Pain Catastrophizing Scale. J Behav Med 1997;20:589-605.

Palermo, TM \& Chambers, CT. Parent and family factors in pediatric chronic pain and disability: An integrative approach. Pain 2005;119:1-4.

Paller, CJ, Campbell, CM, Edwards, RR \& Dobs, AS. Sex-based differences in pain perception and treatment. Pain Med 2009;10:289-299. 
Robinson, ME \& Wise, EA. Gender bias in the observation of experimental pain. Pain 2003;104:259-264.

Sasmaz, T, Bugdayci, R, Ozge, A, Karakelle, A, Kurt, O \& Kaleagasi, H. Are parents aware of their schoolchildren's headache? Eur J Public Health 2004;14:366-368.

Schroeder, S, Hechler, T, Denecke, H, Müller-Busch, M, Martin, A, Menke, A \& Zernikow, B. German Pain Questionnaire for Children, Adolescents and Parents (DSF-KJ) - A multimodal questionnaire for diagnosis and treatment of children and adolescents suffering from chronic pain. [Deutscher Schmerzfragebogen für Kinder, Jugendliche und deren Eltern (DSF-KJ) - Ein multimodaler Fragebogen zur Diagnostik und Therapie chronischer Schmerzen im Kindes- und Jugendalter]. Der Schmerz 2009; 24:23-37.

Sijtsma, K \& van der Ark, LA. Investigation and treatment of missing item scores in test and questionnaire data. Multivar Behav Res 2003;38:505-528.

Sullivan, MJL, Bishop, SR \& Pivik, J. The pain catastrophizing scale: Development and validation. Psychol Assessment 1995;7:524-532.

Sullivan, MJL, Thorn, B, Haythornthwaite, J, Keefe, FJ, Martin, M, Bradley, LA \& Lefebvre, JC. Theoretical perspectives on the relation between catastrophizing and pain. Clin J Pain 2001;17:52-64.

Sullivan, MJL, Tripp, DA \& Santor, D. Gender differences in pain and pain behavior: The role of catastrophizing. Cognitive Ther Res 2000;24:121-134.

Tanaka, JS \& Huba, GJ. A fit index for covariance structure models under arbitrary GLS estimation. Brit J Math Stat Psy 1985;38:197-201.

Vervoort, T, Craig, KD, Goubert, L, Dehoorne, J, Joos, R, Matthys, D, Buysse, A \& Crombez, G. Expressive dimensions of pain catastrophizing: A comparative analysis of school children and children with clinical pain. Pain 2008a;134:59-68. 
Vervoort, T, Goubert, L, Eccleston, C, Verhoeven, K, De Clercq, A, Buysse, A \& Crombez, G. The effects of parental presence upon the facial expression of pain: The moderating role of child pain catastrophizing. Pain 2008b;138:277-285.

Vervoort, T, Goubert, L \& Crombez, G. The relationship between high catastrophizing children's facial display and parental judgment of their child`s pain. Pain 2009;142:142-148.

von Baeyer, CL, Spagrud, LJ, McCormick, JC, Choo, E, Neville, K \& Connelly, MA. Three new datasets supporting use of the numerical rating scale (NRS-11) for children's self-reports of pain intensity. Pain 2009;143:223-227.

Watkins, ER. Depressive Rumination and co-morbidity: Evidence for brooding as a transdiagnostic process. J Rational-Emot Cognitive-Behav Ther 2009;27:160-175.

Whaley, SE, Pinto, A \& Sigman, M. Characterizing interactions between anxious mothers and their children. J Consult Clin Psychol 1999;67:826-836. 


\section{Figure caption}

Figure 1. Standardized factor loadings of the modified three-factor model for mothers and fathers (between parentheses). 


\section{Table S1}

Demographic data and clinical characteristics of the children with chronic pain

\begin{tabular}{|c|c|}
\hline Variable & $\begin{array}{c}\text { Total } \\
\mathrm{N}=128\end{array}$ \\
\hline Age $($ Mean $\pm S D)$ & $11.9 \pm 2.5$ \\
\hline Female $(n(\%))$ & $80(63)$ \\
\hline Primary pain location & $\&$ \\
\hline Head & $97(76)$ \\
\hline Abdomen & $15(12)$ \\
\hline Neck, cervix & $4(3)$ \\
\hline Back & $3(2)$ \\
\hline Extremities & $3(2)$ \\
\hline Face & $2(2)$ \\
\hline Eyes & $1(1)$ \\
\hline Genitals & $1(1)$ \\
\hline More than one primary pain location & $2(2)$ \\
\hline Pain duration in months (Mean $\pm S D$; range) & $\begin{array}{c}32.2 \pm 32.4 \\
(1-144)\end{array}$ \\
\hline Patients on pain medication at pre-assessment (\%) & $106(84)$ \\
\hline Mean pain intensity within the preceding 4 weeks (NRS $0-10$ ) & $7.4 \pm 2.2$ \\
\hline$($ Mean $\pm S D$, range) & $0-10$ \\
\hline Pain-related disability (P-PDI ${ }^{\S}$; Score range: $\left.12-60\right)$ & $35.7 \pm 10.5$ \\
\hline$($ Mean $\pm S D$, range $)$ & $12-60$ \\
\hline $\begin{array}{l}\text { School absence within the preceding } 3 \text { months } \\
(n(\%))\end{array}$ & $87(71)$ \\
\hline Days absent from school within the preceding 3 months & $7.3 \pm 10.0$ \\
\hline (Mean $\pm S D$, range) & $0-60$ \\
\hline
\end{tabular}


Table 2

Descriptives and differences for the total score and the three subscales of the PCS-P for mothers and fathers

\begin{tabular}{|c|c|c|c|c|c|c|c|c|c|}
\hline & $M(S D)$ & Quartile 25 & $\begin{array}{c}\text { Quartile } 50 \\
\text { (Median) }\end{array}$ & Quartile 75 & $\begin{array}{c}\text { Cronbach's } \\
\alpha\end{array}$ & $\begin{array}{c}2 \\
\text { Rumination }\end{array}$ & $\begin{array}{c}3 \\
\text { Magnification }\end{array}$ & $\begin{array}{c}4 \\
\text { Helplessness }\end{array}$ & $F(1,127)$ \\
\hline \multicolumn{10}{|l|}{ Mothers $(\mathrm{N}=128)$} \\
\hline 1. Total & $23.9(10.5)$ & 15.0 & 23.0 & 32.0 & .91 & $0.85^{\star *}$ & $0.79^{* *}$ & $0.91^{* *}$ & $1.99 * \S$ \\
\hline 2. Rumination & $11.0(3.7)^{\mathrm{a}}$ & 8.0 & 11.0 & 14.0 & .85 & & $0.61^{* *}$ & 0.61 & 11.83 ** \\
\hline 3. Magnification & $4.3(2.9)$ & 2.0 & 4.0 & 6.0 & .71 & & & $0.56^{\star *}$ & 0.39 \\
\hline 4. Helplessness & $8.6(5.7)$ & 4.0 & 7.0 & 12.0 & .84 & & & & 2.87 \\
\hline \multicolumn{10}{|l|}{ Fathers $(\mathrm{N}=128)$} \\
\hline 1. Total & $22.1(9.9)$ & 15.0 & 22.0 & 28.75 & .91 & $0.88^{* *}$ & $0.84^{* *}$ & $0.92^{* *}$ & \\
\hline 2. Rumination & $9.8(3.5)^{a}$ & 8.0 & 10.0 & 13.0 & .86 & & $0.67^{\star *}$ & $0.69^{* *}$ & \\
\hline 3. Magnification & $4.5(2.7)$ & 2.25 & 4.0 & 6.0 & .72 & & & $0.66^{* *}$ & \\
\hline 4. Helplessness & $7.9(4.9)$ & 4.0 & 7.0 & 11.0 & .84 & & & & \\
\hline
\end{tabular}

$\S$ A paired T-Test was computed for the statistical comparison of the total score between mothers and fathers.

${ }^{*} p<.05 ;{ }^{* *} p<.01$.

a Based on the results of the MANOVA, mothers displayed higher rumination $(F(1,127)=11.83, p=.001)$ than fathers. Mothers and fathers did not differ in

magnification and helplessness thoughts. 


\section{Table 3}

Bivariate relationship between parental catastrophizing and child's pain characteristics

\begin{tabular}{|c|c|c|c|c|c|c|c|c|c|c|}
\hline & $N$ & Mothers & & & & $N$ & Fathers & & & \\
\hline \multirow{3}{*}{$\begin{array}{l}\text { Child's pain } \\
\text { characteristics }\end{array}$} & & Rumination & Magnification & Helplessness & PCS-P & & Rumination & Magnification & Helplessness & PCS-P \\
\hline & & & & & Total & & & & & Total \\
\hline & & & & & score & & & & & score \\
\hline Pain intensity & 117 & $0.21^{*}$ & 0.14 & 0.17 & $0.20^{*}$ & 117 & 0.09 & 0.01 & 0.14 & 0.10 \\
\hline Pain-related & 122 & 0.12 & 0.07 & 0.10 & 0.11 & 122 & 0.13 & 0.06 & 0.14 & 0.13 \\
\hline disability P-PDI ${ }^{\S}$ & & & & & & & & & & \\
\hline School absence & 117 & 0.07 & 0.10 & 0.12 & 0.12 & 117 & 0.09 & -0.03 & 0.14 & 0.10 \\
\hline
\end{tabular}

${ }^{*} \mathrm{P}<0.05 ;{ }^{* *} \mathrm{P}<0.01 ;{ }^{* * *} \mathrm{P}<0.001$.

$\S$ Paediatric Pain Disability Index (Hübner et al., 2009).

$\S \S$ School absence was assessed as days absent from school within the preceding three months (parental report). 
Table 4

Results of the hierarchical regression analyses for child's pain intensity

\begin{tabular}{|c|c|c|c|c|c|}
\hline Step & Predictors & $\beta$ & $R^{2}$ change & Adj. $R^{2}$ & $R^{2}$ \\
\hline \multicolumn{6}{|c|}{ Pain intensity within the preceding four weeks (Mothers, $n=114$ ) } \\
\hline \multirow[t]{2}{*}{1} & Child's age & 0.02 & 0.002 & -0.02 & \\
\hline & Child's gender & 0.07 & & & \\
\hline 2 & Pain duration & 0.14 & 0.03 & 0.01 & \\
\hline 3 & PCS-P Total score & 0.19 & 0.03 * & 0.04 * & \\
\hline
\end{tabular}

${ }^{* *} p<.001$.

Displayed are the standardized betas.

Missing values due to incomplete questionnaires of the child. 
Table 5

Bivariate relationships between parental pain-related behavior, parental catastrophizing and child's pain characteristics

\begin{tabular}{|c|c|c|c|c|c|c|c|c|}
\hline & $N$ & Mothers & & & $N$ & Fathers & & \\
\hline & & Solicitous & Distracting & Discouraging & & Solicitous & Distracting & Discouraging \\
\hline \multicolumn{9}{|l|}{ Parental } \\
\hline \multicolumn{9}{|l|}{ catastrophizing } \\
\hline Rumination & 124 & $0.46^{\star \star \star}$ & 0.08 & -0.08 & 124 & $0.46^{\star \star \star}$ & $0.27^{* \star}$ & -0.05 \\
\hline Magnification & 124 & $0.40^{\star * \star}$ & 0.13 & 0.07 & 124 & $0.38^{* * *}$ & $0.23^{*}$ & 0.11 \\
\hline Helplessness & 124 & $0.22^{*}$ & 0.06 & $0.21^{*}$ & 124 & $0.38^{* * *}$ & $0.18^{*}$ & 0.16 \\
\hline PCS-P Total & 124 & $0.39^{\star \star \star}$ & 0.10 & 0.10 & 124 & $0.46^{\star \star \star}$ & $0.25^{\star \star}$ & 0.09 \\
\hline
\end{tabular}




\section{Table 6}

Results of the hierarchical regression analyses to predict pain-related parent behavior

\begin{tabular}{|c|c|c|c|c|c|}
\hline Step & Predictors & $\beta$ & $R^{2}$ change & Adj. $R^{2}$ & $R^{2}$ \\
\hline \multicolumn{6}{|c|}{ Solicitous responses (Mothers, $n=112$ ) } \\
\hline & & & & & 0.17 \\
\hline \multirow[t]{2}{*}{1} & Child's age & $-0.21 *$ & $0.07 *$ & 0.05 * & \\
\hline & Child's gender & -0.07 & & & \\
\hline \multirow[t]{2}{*}{2} & Pain duration & 0.10 & 0.05 & 0.09 & \\
\hline & Pain intensity & 0.09 & & & \\
\hline 3 & PCS-P Total score & 0.27 * & $0.07^{*}$ & $0.15^{*}$ & \\
\hline
\end{tabular}

Solicitous responses (Fathers, $n=112)$

0.33

\begin{tabular}{|c|c|c|c|c|}
\hline \multirow[t]{2}{*}{1} & Child's age & -0.20 * & $0.14^{* *}$ & $0.14^{* *}$ \\
\hline & Child's gender & -0.20 * & & \\
\hline 2 & Pain duration & -0.04 & 0.001 & 0.14 \\
\hline & Pain intensity & -0.04 & & \\
\hline 3 & PCS-P Total score & $0.45^{* *}$ & $0.20 * *$ & $0.30^{* *}$ \\
\hline
\end{tabular}

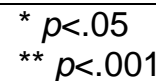

** $p<.001$

Solicitous, distracting and discouraging responses were assessed by use of the Pain-Related Parent Behavior Inventory (PPBI) (Hermann et al., 2008). 
Table 6 (contd.)

\begin{tabular}{|c|c|c|c|c|c|}
\hline Step & Predictors & $\beta$ & $R^{2}$ change & Adj. $R^{2}$ & $R^{2}$ \\
\hline \multicolumn{6}{|c|}{ Distracting responses (Mothers, $n=114$ ) } \\
\hline & & & & & 0.08 \\
\hline \multirow[t]{2}{*}{1} & Child's age & -0.24 & 0.05 & 0.04 & \\
\hline & Child's gender & 0.06 & & & \\
\hline \multirow[t]{2}{*}{2} & Pain duration & -0.11 & 0.04 & 0.02 & \\
\hline & Pain intensity & 0.13 & & & \\
\hline 3 & PCS-P Total score & 0.07 & 0.04 & 0.004 & \\
\hline \multicolumn{6}{|c|}{ Distracting responses (Fathers, $n=112$ ) } \\
\hline & & & & & 0.07 \\
\hline \multirow[t]{2}{*}{1} & Child's age & -0.18 & 0.06 * & $0.05^{*}$ & \\
\hline & Child's gender & -0.10 & & & \\
\hline \multirow[t]{2}{*}{2} & Pain duration & -0.07 & 0.008 & 0.04 & \\
\hline & Pain intensity & 0.04 & & & \\
\hline 3 & PCS-P Total score & $0.21 *$ & $0.04 *$ & $0.07^{*}$ & \\
\hline
\end{tabular}


Table 6 (contd.)

\begin{tabular}{|c|c|c|c|c|c|}
\hline Step & Predictors & $\beta$ & $R^{2}$ change & Adj. $R^{2}$ & $R^{2}$ \\
\hline \multicolumn{6}{|c|}{ Discouraging responses (Mothers, $n=113$ ) } \\
\hline & & & & & 0.10 \\
\hline \multirow[t]{2}{*}{1} & Child's age & -0.01 & 0.05 & 0.03 & \\
\hline & Child's gender & $-0.21 *$ & & & \\
\hline \multirow[t]{2}{*}{2} & Pain duration & -0.08 & 0.03 & 0.04 & \\
\hline & Pain intensity & -0.14 & & & \\
\hline 3 & PCS-P Total score & 0.16 & 0.02 & 0.05 & \\
\hline \multicolumn{6}{|c|}{ Discouraging responses (Fathers, $n=112$ ) } \\
\hline & & & & & 0.02 \\
\hline \multirow[t]{2}{*}{1} & Child's age & 0.04 & 0.01 & -0.004 & \\
\hline & Child's gender & -0.13 & & & \\
\hline \multirow[t]{2}{*}{2} & Pain duration & 0.01 & 0.002 & -0.02 & \\
\hline & Pain intensity & 0.04 & & & \\
\hline 3 & PCS-P Total score & 0.09 & 0.008 & -0.02 & \\
\hline
\end{tabular}

${ }^{*} p<.05$

${ }^{* *} p<.001$. 


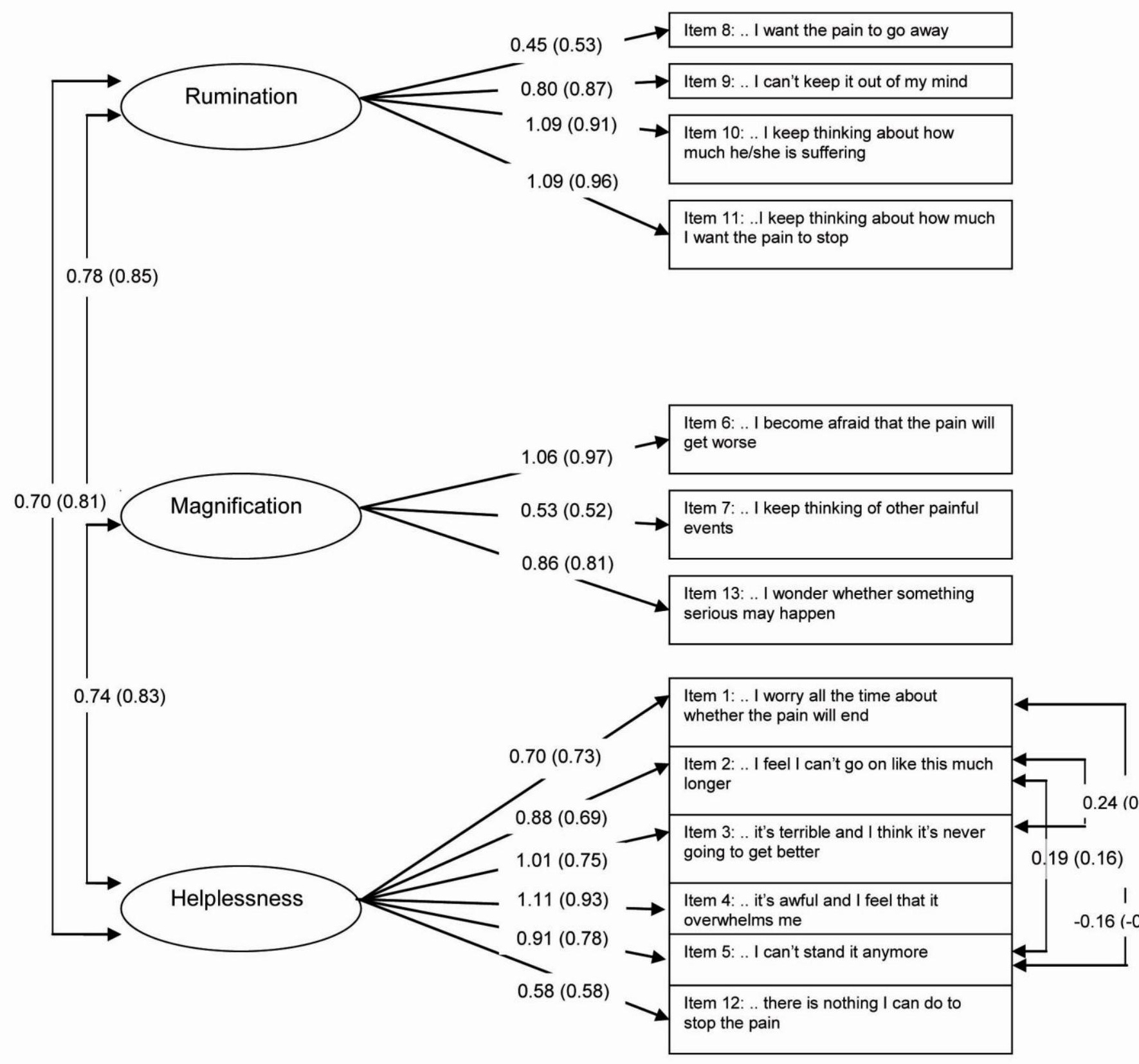

